\title{
An expressive art group intervention for sexually abused adolescent females
}

\author{
Maretha Visser* and Jessica du Plessis \\ Department of Psychology, University of Pretoria, South Africa \\ *Corresponding author, email: Maretha.visser@up.ac.za
}

\begin{abstract}
Objective: South Africa has a high prevalence of sexual abuse of children and adolescents. Among the numerous adverse consequences of sexual abuse is the difficulty survivors may experience in developing a positive self-esteem and maintaining positive relationships. In a low resource setting, an expressive art group intervention tailored for female adolescents who have been sexually abused was implemented and its value explored.

Method: Six adolescents met for ten weekly sessions which included expressive art activities, followed by reflective group discussions. The value of the intervention was explored using a qualitative research design with limited quantitative data.

Results: The participants reported that the group intervention relieved their sense of isolation and contributed to their ability to express emotions and develop self-awareness. Participants reported more positive self-esteem and improved interpersonal closeness. The intervention helped participants to find new meaning in painful experiences which contributed to personal growth.
\end{abstract}

Conclusions: The group dynamics, expressive art activities and reflective group discussions contributed to the therapeutic value of the intervention. The expressive art group intervention showed value as an alternative therapeutic strategy in a low resource setting for female adolescents that have experienced sexual abuse. An experimental design could follow to confirm the effectiveness of the intervention. 
Key words: Childhood sexual abuse. Adolescents. Self-esteem. Interpersonal closeness. Group intervention. Expressive art activities. Mixed methods design.

\section{Background}

South Africa has one of the highest rates of sexual abuse in the world, with adolescent girls between 12 and 17 being particularly at risk (Moffet 2006, Penning and Collings 2014, Petersen, Bhana and McKay 2005). Police Crime Statistics (SAPS 2014) indicates that 62 649 sexual offences were reported countrywide for the year 2013/2014 of which 18524 were cases of child rape (30\% of the total) - which means 51 cases per day (Wilkinson 2014). Although there are no formal statistics of the prevalence of child sexual abuse in South Africa, girls under the age of 18 typically constitute approximately $40 \%$ of reported rape and attempted rape cases (Hirschowitz, Worku and Orkin 2000, Rape Crisis 2012). A study conducted in the Eastern Cape found that $70.9 \%$ victims of sexual offences were girls under the age of 20 years. Of these $46.3 \%$ were girls under the age of 16 years, $22.9 \%$ girls younger than 11 years and 9.4\% were five years and younger (Meel 2008). It is widely accepted that sexual offences are underreported (Robertson 2011), therefore the prevalence estimates are grossly underestimated (Jewkes, Penn-Kekana and Rose-Junius 2005; Rape Crisis 2012).

The concept of sexual abuse is defined as follows:

“a) sexually molesting or assaulting a child or allowing a child to be sexually molested or assaulted; b) encouraging, inducing or forcing a child to be used for the sexual gratification of another person; c) using a child in or deliberately exposing a child to sexual activity or pornography; or d) procuring or allowing a child to be procured for commercial sexual exploitation or in any other way participating or assisting in the commercial sexual exploitation of a child" (Children's Act 38 2005, p. 18). 
Sexual abuse and exploitation can therefore take on many forms, including situations where children are abused sexually by a caregiver or relative at home, sexually molested on the way to school, made to have sex in exchange for food, lured into sex online, or trapped into sexual slavery by organised groups (Radford, Allnock and Hynes 2014).

Given the number of children and adolescents that are affected by this trauma, it represents a mental health priority (Kaminer 2006, Olafson 2014). The negative impact of childhood sexual abuse (CSA) is well documented. CSA often has devastating consequences for emotional, somatic, behavioural, cognitive and relational development (Gregorowski and Seedat 2013, Sadock and Sadock 2007). CSA has been linked to the development of psychological disorders such as post-traumatic stress disorder (PTSD), dissociative disorders, depression, generalised anxiety, separation anxiety, anti-social behaviours, substance abuse, eating disorders and self-destructive behaviour (Carey et al. 2008, Oz 2010, Sadock and Sadock 2007, Suliman et al. 2009). Notably, sexual abuse has the highest causal rate of PTSD of any trauma (Olafson 2011). While the nature, length and severity of sexual abuse will differ from child to child (Rodriguez-srednicki 2002), and children and adolescents respond differently to sexual abuse, the detrimental effects of any kind of sexual abuse can be longlasting and pervasive. Choi et al. (2015) found that CSA was significantly associated with depression and PTSD in later life, mediated by maladaptive coping strategies.

CSA often has a negative influence on a child's self-esteem and interpersonal relationships (Sadock and Sadock 2007, Spies 2006). Premature sexual contact can be traumatic and confusing for a child. It may cause the child to internalize certain false truths about him/herself and the world, such as that he/she are not worthy of love and protection and is responsible for the abuse. The child may feel guilty and shameful over something that was 
beyond his/her control (Mash and Wolfe 2012). Abused children often present with feelings of worthlessness and self-hatred (Sadock and Sadock 2007).

Children exposed to sexual abuse may yearn for and fear intimate contact at the same time. This may manifest in them isolating themselves as protection from re-experiencing the trauma. Social contact can make them anxious. Others may act out and engage in inappropriate sexual activities (Spies 2006).

The high prevalence of sexual abuse and the severe and damaging consequences in a child and adolescent's life require psychological intervention at the earliest stage possible to facilitate healing (Petersen et al. 2005; Radford et al. 2014). In a review of treatment literature, Edwards (2009) found that individual psychotherapy is the most common treatment approach for sexual abuse. Trauma-Focused Cognitive Behavioural Therapy (TF-CBT) and Eye-Movement and Desensitising Reprocessing (EMDR) have been identified as the most effective in the treatment of sexual abuse (Farham et al. 2013, Radford et al. 2014). Play therapy and brief-term interventions are also often used when working with traumatised children (Radford et al. 2014). These individually focused trauma interventions may not be appropriate in the South African context with large numbers of abused children and adolescents and a lack of professional resources.

A critical focus of treating sexual abuse in psychotherapy is on exploring the traumatic incident(s) and expressing emotions connected to the trauma (Ford and Cloitre 2009, Hajiyiannis and Robertson 1999). These techniques involve re-exposure to the traumatic event and should only be used by trained professionals (Lilienfeld et al. 2003). Trauma counsellors without a clear theoretical understanding to guide trauma re-construction are at risk for re-traumatising their clients (Kaminer 2006). 
Furthermore, most evidence-based treatments for sexual abuse were developed in resource-rich contexts (Radford et al. 2014). In South Africa there are many social and economic barriers that prevent survivors of sexual abuse from gaining access to the treatment they need (Smith et al. 2010). Given the limited therapeutic resources and lack of trained professionals, systematic and resource-effective treatment programmes are needed which are context appropriate (Petersen et al. 2005). Petersen et al. (2005) highlight the value of community-based interventions and of creating social networks for youth who have been sexually abused in order to protect them and promote healing.

The value and usefulness of group interventions in various mental health contexts has been well documented (Sturgeon and Keet 2010). The therapeutic elements of group therapy include the sense of shared experiences, interpersonal learning, modelling of behaviour and instillation of hope (Yalom 1985). Expressive art therapy is often done in a group context as part of trauma counselling with children and adolescents (Coholic 2010, Murphy 2001, Pifalo 2011). Expressive art therapy is defined as the use of various forms of art within the context of psychotherapy and counselling (Malchiodi 2005). Expressive art therapy with sexually abused children and adolescents offers a safe space to explore feelings, which is less intense than verbal therapy. Within such a relationship, the art materials or images provide a means of expressing and recognising the feelings resulting from a traumatic experience (Murphy 2001).

Research indicates that little has been published on culturally appropriate communitybased group work within the South African context (Becker and Duncan 2010, Sturgeon and Keet 2010). The same applies to expressive art activities in a group context for adolescents being sexually abused. 
In this research, a group intervention using expressive art activities to increase selfesteem and interpersonal relationships was developed and implemented in a low-resource area for adolescent girls who had been sexually abused. The aim of the research was to explore the feasibility of the group intervention as an alternative treatment for sexual abuse in low-resourced areas.

\section{Methods}

This section contains a description of the aim of the study, the development, implementation and strategies to evaluate the group intervention. It also contains the data analysis and ethical considerations.

\section{Aim}

The aim of the research was to develop, implement and explore the feasibility of a group intervention using expressive art activities to improve the self-esteem and interpersonal relationships of female adolescents who were sexually abused. The feasibility was explored through a process and outcome evaluation of the intervention on a small group of participants.

\section{The development of the intervention}

The intervention was planned as a group intervention where the therapeutic qualities of group dynamics were included (Yalom 1985). These involve a non-judgmental and accepting climate to make it possible for adolescents to explore many aspects of themselves and gain self-acceptance as the group validates the individual (Collie et al. 2006). Group members who experience similar trauma can support one another through understanding and modelling behaviour (Yalom 1985). 
The objective of the intervention was to establish safety, emotional self-regulation, integration of the self, re-engagement with relationships and enhancement of positive affect goals in the management of trauma (Cook et al. 2005, Ford and Cloitre 2009, Radford et al. 2014). Rather than focusing on the trauma, the intervention focused on strengths, self-esteem development, building interpersonal trust and positive coping mechanisms (Tierney and McCabe 2002). However, the group climate remained a safe space in which participants could verbalise what had happened to them if they felt they needed to.

Each session consisted of the following structure:

1) Reflection on experiences of the previous session.

2) Expressive art activity: Each session introduced an expressive art activity chosen or developed according to the needs of the group. The art activities were drawn from established literature (Bowers 2011, Coholic 2010, Pifalo 2011) and used low-cost material such as paper, glue and coloured crayons. Art activities focused on selfawareness, positive and negative qualities, personal values, emotional expression and regulation, personal strengths and coping mechanisms. The activities encouraged self-exploration and self-expression (Backos and Pagon 2011).

3) Reflective discussion: The discussion of the activities resulted in sharing experiences and feelings. The facilitators asked challenging questions to assist participants to change their negative interpretations and to develop a positive outlook.

The content of the ten sessions of the intervention is outlined in table 1. 
Table 1 Summary of sessions

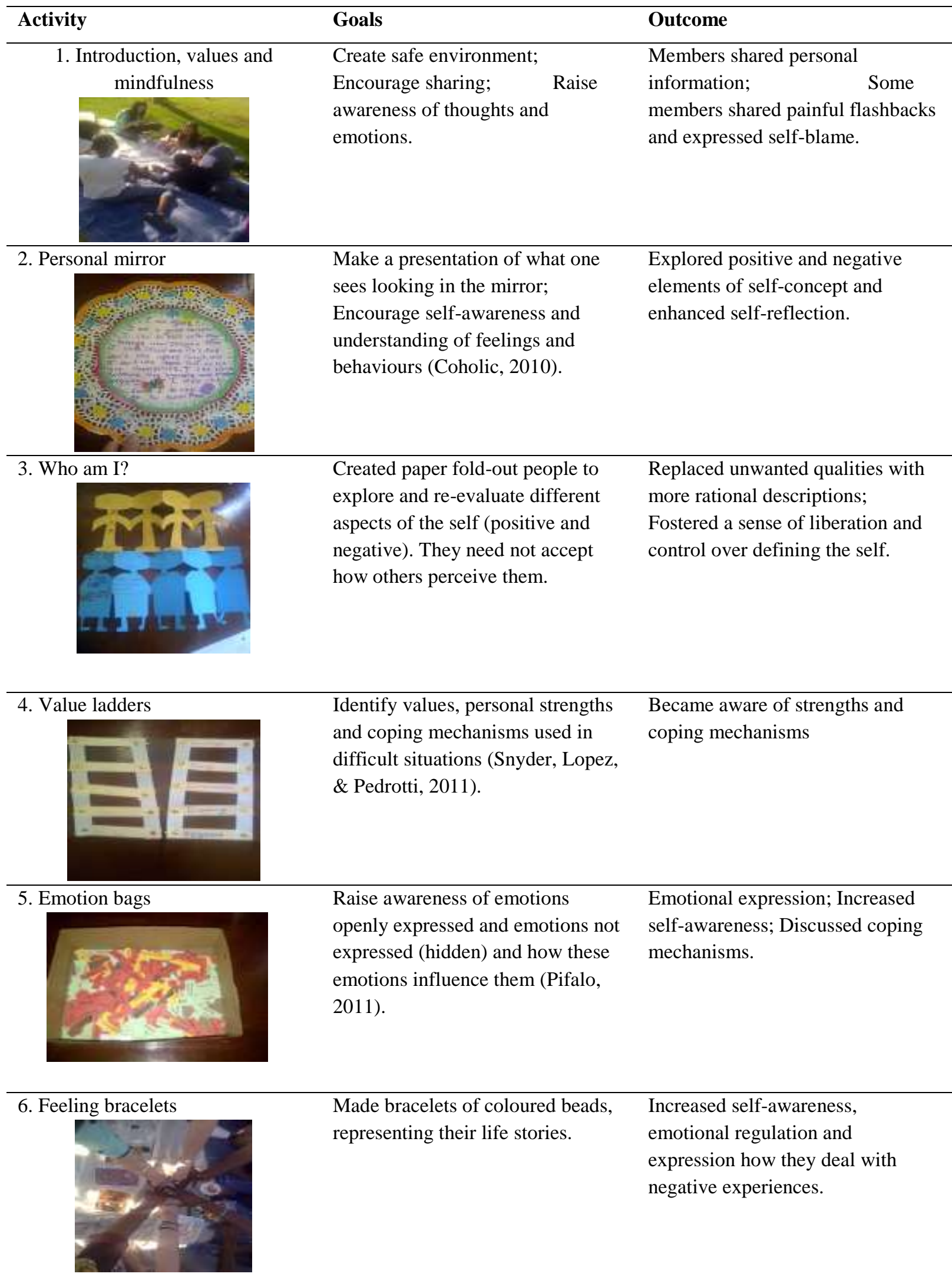




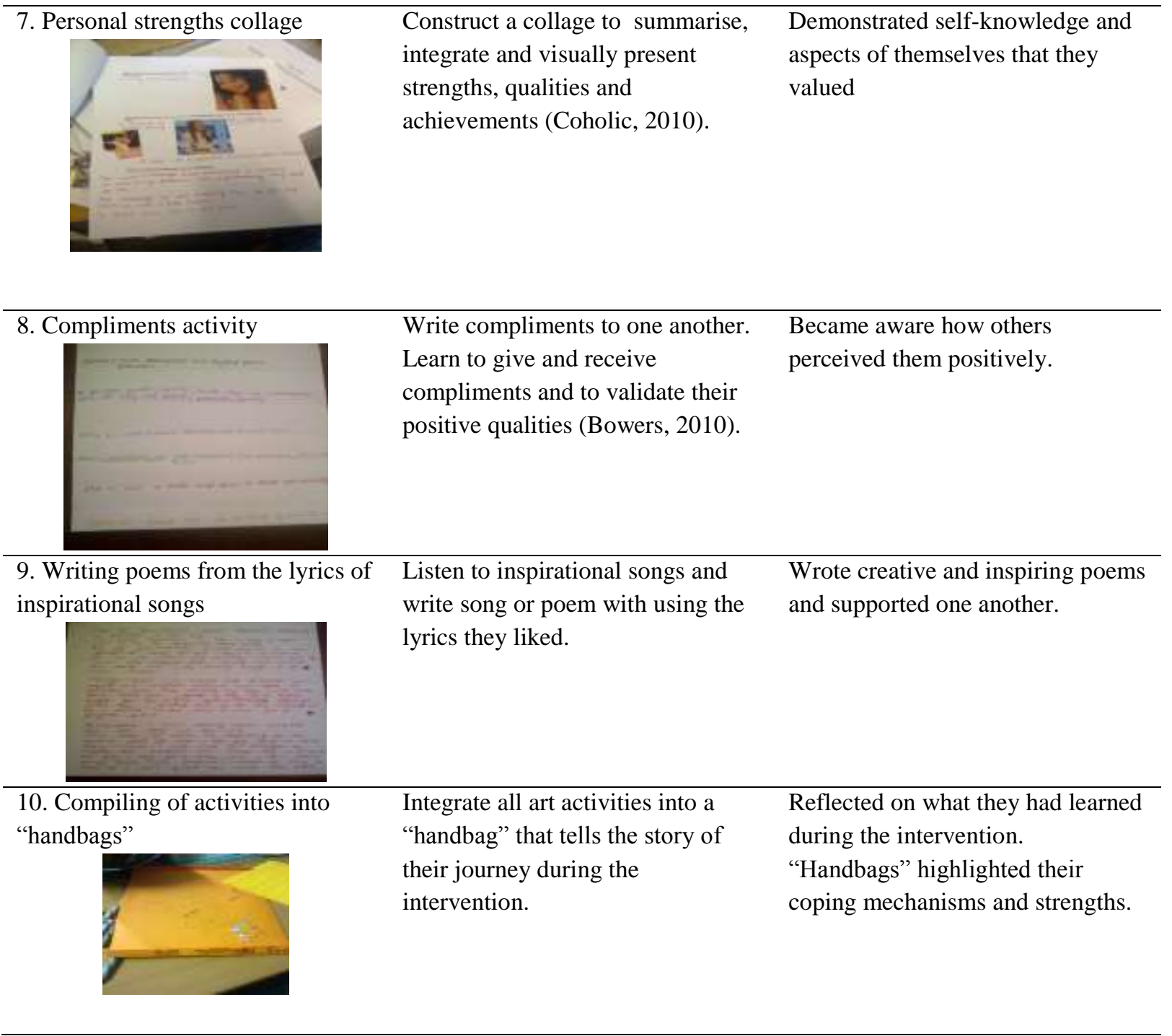

\section{Implementation of the intervention}

The intervention was implemented at the Itsoseng clinic, Mamelodi East, in Tshwane. The township consists of large informal housing areas and is home to a low- to middle-class community. The community-based clinic, operated by the University of Pretoria, is open to all community members and provides free psychological services.

Participants recruited for the intervention were part of the clinic's client base and presented with problems related to sexual abuse. The following inclusion criteria were used: 
1. Participants had to be female survivors of sexual abuse (most of the clients presenting with sexual abuse at the clinic were females);

2. Participants had to be between the ages of thirteen and eighteen;

3. They had to have received at least one session of individual trauma counselling at the clinic (to ensure that they had been debriefed and received orientation about the group intervention);

4. Participants had to be emotionally relatively stable and in contact with reality as determined by the clinic's standard mental state evaluation process;

5. Participants had to be able to attend the weekly group sessions at the clinic.

The intervention started with eight participants. Three of them dropped out after two sessions because of lack of transport and one joined in session four. Six girls participated in most of the sessions. They were between the ages of 13 and 18 years old (average age of 15.8 years). Two participants were in grade 8 (P3 and P5) and the others were in grade 11 and 12 (P1, P2, P4, P6).

The participants met weekly for 90 minutes at the clinic, over a period of 10 weeks. The intervention was facilitated by four female Masters level Psychology students. All four facilitators were present each session, but the role of the lead facilitator rotated. The lead facilitator explained the art activity and facilitated the reflective discussions. The other facilitators joined in the activities to model how it should be done and to provide additional support. The researcher was one of the students who facilitated the group. The facilitators participated in weekly supervision sessions with a registered psychologist where they discussed what happened in the group and received assistance in planning for the next group activities. 


\section{Evaluation of the intervention}

To evaluate the process and outcome of the intervention, a qualitative research design with limited quantitative data was used. Various data sources were used to strengthen the results (Creswell 2003).

Group process notes: The facilitators kept a reflective journal that documented the group processes and the personal growth of the participants in each session. The facilitators' process notes were analysed to understand the group dynamics and supplement information gathered from the pre- and post-interviews.

Pre- and post-intervention individual interviews: The researcher conducted a semistructured interview (Smith 2004) with each participant before the group intervention started as well as after the intervention. The pre-intervention interviews focused on how the abuse influenced the participants' self-esteem and relationships. The post-intervention interviews focused on how participants experienced the intervention and the effect it had on their selfesteem and relationships. Interviews were conducted in English. The participants were semifluent in English. An interpreter was present to translate words into Sepedi when the participant asked for clarity. Interviews were audio-recorded with the participants' permission, and transcribed for analysis.

Pre-and post-intervention quantitative scales: Two scales were included in the interviews before and after the intervention to measure differences in participants' selfesteem and relationships to strengthen the qualitative results.

The Rosenberg Self-Esteem Scale (RSE) (Rosenberg 1965) is a 10-items scale that measures the extent to which one values and feels content with oneself on a four-point Likerttype scale ranging from 1 (totally disagree) to 4 (totally agree). The RSE has a high internal 
reliability ( $\alpha=.92)$ and has shown a modest correlation with mood measures (Rosenberg 1979). The RSE is commonly used in South African samples. A Cronbach alpha coefficient of 0.75 was obtained in a South African sample (Makin et al. 2008).

The Interpersonal closeness scale (part of the Interpersonal Relationships Questionnaire (IRQ)) is a 24-item scale that elicits information about how people disclose information about themselves and interpersonal closeness. In this scale, interpersonal closeness refers to being "connected" to others and being willing to share personal experiences (Garthoeffner, Henry and Robinson 1993). The scale was developed to evaluate the effects of an interpersonal intervention. Items are rated on a 6-point Likert-type scale ranging from 1 (totally disagree) to 6 (totally agree). According to Garthoeffner et al. (1993) the scale and subscales provided reliable and valid measures of the quality of interpersonal relationships in young adults. Unfortunately, there is no validation of the scale in the South African context. Even though, it was found to be useful because the items assess basic characteristics of relationships that can be the same across cultures. Additionally, no norms associated with a specific context were used.

\section{Data analysis}

Thematic analysis (Braun and Clarke 2006) was used to explore and interpret the group process notes and interviews with participants. Thematic analysis involves searching across interviews to find repeated patterns of meaning. Themes on how participants experienced abuse, how their experiences changed from pre- and post-interview and what contributed to these changes were identified in the analysis. The process of data analysis involved: identification of possible themes, coding of data, sorting of codes into themes, reviewing and refining the themes and describing and analysing the themes (Braun and Clarke 2006). The validity of the data interpretation was enhanced by having two independent researchers 
analyse the data. They discussed the themes identified and reached consensus on the interpretation. The interpretation of the data was also validated by sharing the results with the participants in the format of member checking (Gravetter and Forzano 2009). This was done in a follow-up session after the intervention. The participants agreed with the researcher's interpretation of the data.

The pre- and post-scores of each participant on the quantitative scales are presented in graphs. Related samples Wilcoxon sign rank tests (non-parametric tests) were used to determine differences before and after the intervention.

\section{Ethical considerations}

The research was ethically approved by the ethics committee of the Faculty of Humanities, University of Pretoria. Participants and their parents or guardians gave written and verbal informed consent to participate in the group intervention and the research. The implementation of the group intervention was supervised by a registered psychologist. Confidentially and anonymity of participants was adhered to during the research process (Wassenaar 2006). Group members agreed to respect one another and to keep all personal information discussed in the group confidential.

\section{Results}

Themes obtained from the facilitators' group process notes, pre-and post-semi-structured interviews and quantitative results are presented as part of the process and outcome evaluation. 


\section{Group processes}

During the course of the group development, the facilitators witnessed processes of trust, commitment, self-disclosure and empathy unfold. In the first session one of the older participants disclosed her painful experience of sexual abuse and was supported by the facilitators. This created a climate of trust and empathy in which participants felt secure to share personal information and express their emotions.

The younger participants were shy and introverted and would only share information when asked to do so. The older participants took a supportive role and encouraged them to share their feelings and thoughts. As the intervention progressed the younger girls opened up more. By the sixth session, they joined the informal conversation after the session.

Participants shared experiences of loneliness and sadness, feeling misunderstood and inability to express their emotions. In response to these needs, the facilitators chose and/or created expressive activities aimed at creating space for members to express both positive and negative emotions. This facilitated a process of self-awareness and emotional expression, which may have helped them in understanding and regulating their emotions.

The facilitators noted the improved ability of each participant to communicate their needs, express their emotions, listen to others and show empathy. The girls called their group the "fashion girls". They often complimented one another on their appearance. Towards the end of the intervention one of the participants suggested we change the group name to "the powerful fashion girls". This indicated to the facilitators a sense of empowerment and courage that has developed in the group. 


\section{Themes from interviews}

The main themes identified from the pre- and post- intervention interviews (pre-I, post-I) are summarised in table 2 . The first few themes illustrate processes that were helpful in facilitating change, followed by themes on the outcome of the intervention. Themes will be outlined and verbatim quotes given to illustrate participants' experiences of the intervention.

Table 2 Thematic analysis

Processes that were helpful:

Isolation versus belonging

A sense of shared experiences

Modelling behaviour

Emotional repression versus emotional expression

Self-awareness

Outcome of intervention:

Improved self-esteem

Improved relationship

Value of group intervention for participants

\section{Theme 1: Isolation versus Belonging}

Before the intervention participants tended to feel isolated and that people did not understand them. The traumatic experience was like a barrier between them and other people, as illustrated in the quote:

"Most of the time I feel alone because people don't know what I have been through so it's not that easy to engage with them. It's not easy for me to tell them what I have been through. It's embarrassing and I don't want to be a burden" (P4, pre-I).

The group intervention created a context for participants to share their experiences and to receive support and understanding. This created a sense of belonging: 
"In the group I meet someone who cares about what happened to me" (P1, post-I).

"I really wanted to talk to someone who cares about how Ifeel... It's nice to know that here are people who care about what other people are feeling and thinking” (P2, post-I).

\section{Theme 2: A sense of shared experiences}

It was therapeutic for participants to realise that there were other young people with similar experiences. They gained support and strength in knowing others had been through similar trauma and cope relatively well with their emotions:

"Listening to other people tell their stories, I realize I am not the only one that hurts. It was a lot easier to accept what happened" (P4, post-I).

"At the beginning it was hard to talk about my feelings and my experiences, but then I came to realize that I am not the only person who had been through a bad situation" (P3, post-I).

\section{Theme 3: Modelling behaviour}

Older participants served as role-models for the younger ones by expressing their feelings and providing support and encouragement to cope. The younger girls looked up to the older members as examples of people who managed their lives despite the trauma. This gave others courage:

"Ifeel I have suffered so much that I wanted to die, but then I think there are others who have suffered more ... and that makes me think that if other people can live through it and come out the other side... so can I" (P4, post-I). 


\section{Theme 4: Emotional repression versus Emotional expression}

Before the intervention participants reported strong feelings of sadness and anger which they had difficulty to regulate. Any situation could trigger these emotions:

"Sometimes I eat a lot and sleep a lot and have a short temper. After it happened I find it difficult to laugh and joke and I became very sensitive. Sometimes someone will say just a little thing and I will cry and be very angry" (P2, pre-I).

Participants tried to ignore and repress their feelings which isolated them from others:

"I forget about what happened to me. But when I hear someone did it to someone else also, I feel bad and then it comes back. When I think of it I cry and I don't want to talk to anyone, I want to be alone. I think to forget is a good thing because if you always think about it, you will always hurt” (P3, pre-I).

During the intervention they could express these bottled up emotions and felt relieved. This contributed to their ability to regulate their emotions:

“I could share my feelings with someone and I don't need to keep it all in” (P4, post-I).

"I felt like I was free, I felt like I could say anything and be myself. It felt like I was talking to people who I had known for a long time” (P6, post-I).

"When I came here I was so down and I didn't even see the good in me and I was angry all the time. Since I came here I off-loaded a lot of weight that I was carrying around" (P6, postI).

\section{Theme 5: Improved self-awareness}

The expressive art activities helped participants to explore and become aware of positive and negative characteristics, strengths, values and ways of coping: 
"I have learnt so many things about other people and about myself... mostly about myself and how to communicate with other people” (P1, post-I).

"For me it was life-changing. It made me understand myself a little better and to just take one step at a time” (P6, post-I).

"It made me realize things about myself... I didn't realize how strong I was until I came here to this group. It made me proud of myself that I can still stand on my own two feet after everything I have been through" (P4, post-I).

\section{Theme 6: Improved self-esteem}

Acceptance in the group, self-awareness and emotional expression resulted in a positive impact on self-esteem. The participants discovered their strengths and developed coping skills which contributed to self-understanding and self-confidence:

"The support group really changed me in a lot of ways. It helped me become confident and nowadays I don't let small things get to me. I couldn't even walk in the streets, but ever since I came here, I've been putting on my make-up and smile, saying that this is the stronger me." (P5, post-I).

"I value myself and there are also other people who value me" (P4, post-I).

The quantitative results confirmed the increased self-esteem of the participants. Four of the five participants showed increased self-esteem scores, though the difference for the group was not statistically significant. (The small sample size needs to be kept in mind. Five participants completed the pre-and post-scales because the participant that joined the group in session 4 did not complete the pre-assessment.) 


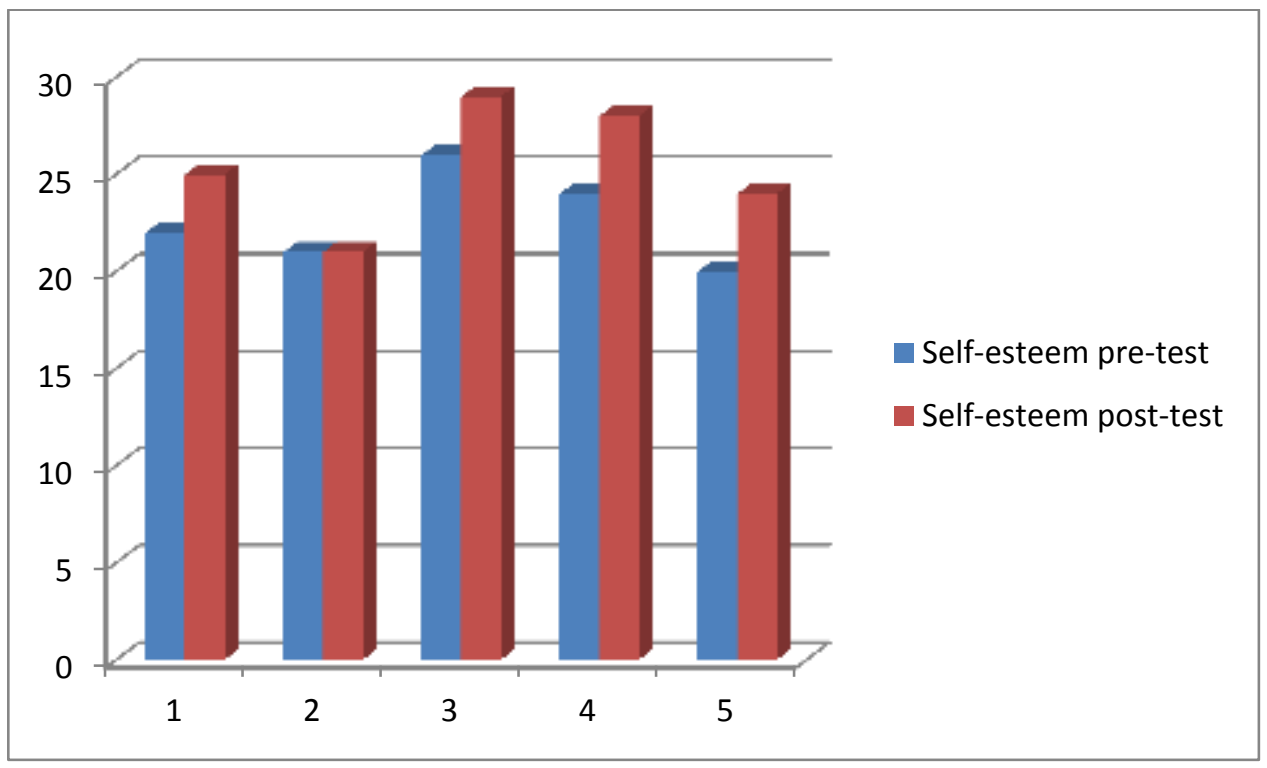

Graph 1 Increase in self-esteem scores of participants

\section{Theme 7: Improved relationships}

The positive relationships in the group helped the participants to improve their relationships with people outside the group. Participants mentioned how their relationships with friends and family improved. It motivated some participants to spend time with friends and share personal information with others instead of isolating themselves:

"The group helped me to treat people better and to start talking about my emotions" (P1, post-I).

"The group helped me to have a better relationship with my mother" (P1, post-I).

"I used to sleep all day, to avoid being around people, drinking a lot...thinking bad things about myself. But now I feel good things. I don't sleep so much anymore and would rather be around friends" (P2, post-I). 
"The group taught me to believe in myself so when I see other people I can smile and say hello, rather than staying alone and locked up in my room" (P5, post-I).

Graph 2 revealed that all five participants reported more interpersonal closeness after the intervention $(\mathrm{p}<0.05)$.

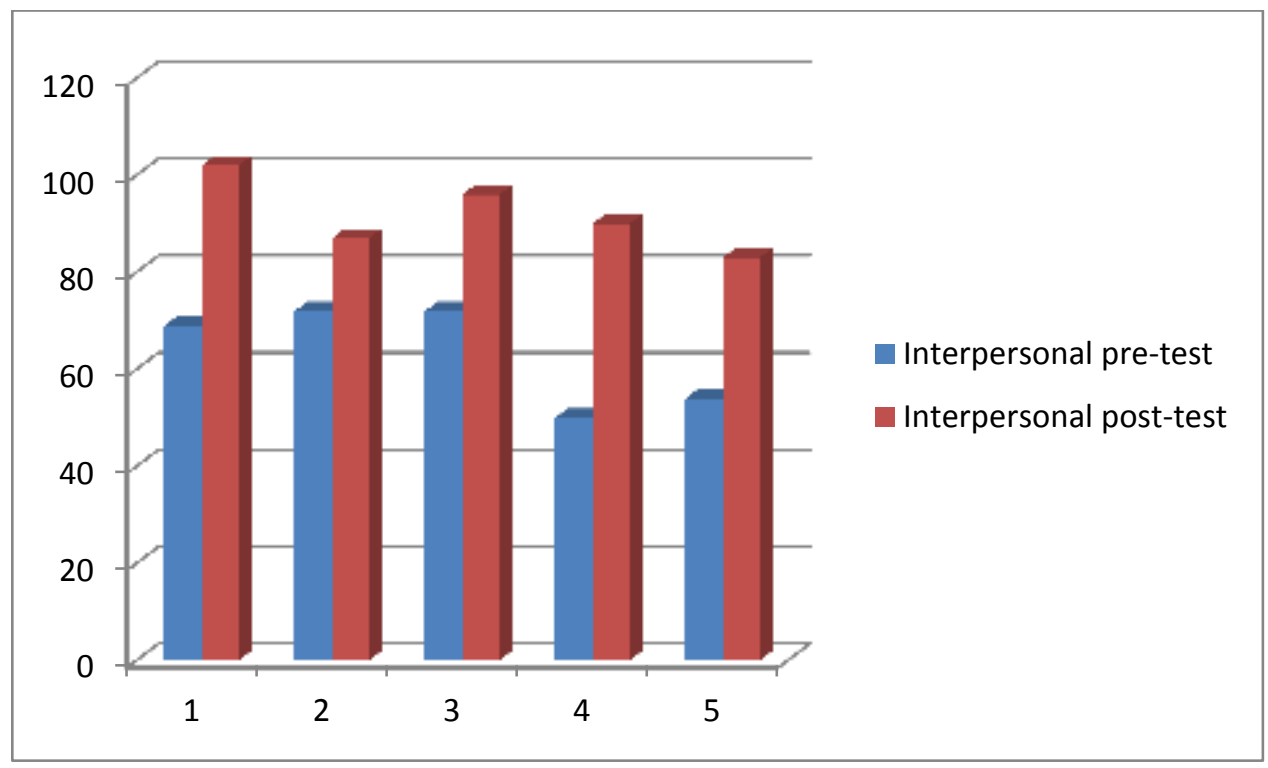

Graph 2 Increase in interpersonal closeness scores of participants

\section{Theme 8: Value of group intervention for participants}

The participants felt proud and a sense of accomplishment when they reflected on their journey during the intervention:

"It reminds me of the big steps I have taken. It has helped me to be less shy... I can look at you now because I am proud of myself"' (P5, post-I).

The progression in the group is visible if quotes before and after the intervention are compared: 
"I sometimes feel as if I don't deserve to be alive and sometimes I feel great, especially when I am with my friends. But when I'm alone I sometimes feel as if I could die” (P2 pre-I).

In her post-intervention interview she said the following:

"I feel I have suffered so much that I wanted to die. I learned more about myself. I learned that I need to go on with life and not to kill myself for something that is not my fault. It gave me courage to go with my dreams" (P2 post-I).

The participants appreciated the indirect ways of dealing with trauma that the art activities and group interaction provided compared to individual counselling where the focus is on re-telling their story:

"I see intervention group is better than alone counselling because they ask too many questions that you don't want to talk about. They try to make you talk about things you want to forget ever happened to you” (P3, post-I).

The group dynamics, art activities, and reflective discussions encouraged self-awareness and emotional expression of participants, which had a positive impact on self-esteem and interpersonal relationships. The group intervention thus helped participants to reconstruct their lives and re-engage in relationships.

\section{Discussion}

The goal of the research was to explore the feasibility of using an expressive art group intervention to help female adolescents to recover from sexual trauma - specifically to improve their self-esteem and interpersonal relationships. The processes that were helpful to facilitate change and the change that were noted will be discussed as well as the value of the group intervention in a resource-limited area. 
Based on the themes identified from the interviews and group process notes three processes that facilitated change in the participants were identified, namely the group dynamics, the expressive art activities and the reflective discussions lead by the facilitators.

The group dynamics created an accepting and empathetic group climate shared with peers with similar experiences. This lessened their feelings of isolation and encouraged them to participate in group activities to explore their strengths, values and coping mechanisms. Yalom (1985) emphasized that these group processes contributed to the therapeutic value of group interaction. The group context presented the participants with a corrective interpersonal experience in which members were able to model behaviour, learn from and support one another. This assisted the participants to restore their ability to relate to others. Ford and Cloitre (2009) described restored relationships as important in the recovery after experiencing trauma.

The expressive art activities provided participants a platform for self-exploration, increased self-awareness and emotional expression. Survivors of sexual abuse are often left with a vast array of emotions, including anger, sadness, guilt and/or loneliness which they find difficult to express (Pifalo 2011). They often feel too threatened or embarrassed to talk about the sexual abuse and they do not want to burden others. Thus, they bottle up powerful emotions. The expressive art activities created the opportunity to explore and express these difficult emotions in an indirect and non-threatening way, also emphasized by Murphy (2001).

The reflective discussions lead by the facilitators challenged participants to change their negative perspective, to focus on positive ways of coping and to discover positive aspects of themselves which contributed to improved self-esteem. These discussions allowed for a holistic exploration of their self-esteem as well as receiving feedback on how others perceive 
them. These processes contributed to some change in their perspectives and helped them to attach new meaning to negative experiences.

From the interviews and quantitative results it can be concluded that the intervention contributed to some change in the participants' self-esteem and interpersonal relationships. The adolescent girls developed new ways of evaluating themselves and their experience of trauma. They expressed more confidence and emotional regulation. The participants also reported that their relationships improved with their family and peers. This was confirmed in the significant improvement on the interpersonal closeness scale. A major goal in the process of healing after sexual abuse involves restoring meaningful social connections (Ford and Cloitre 2009, Saiger, Rubenfeld and Dluhy 2008). This intervention assisted the participants in restoring their ability to relate to others. The intervention thus contributed to many of the goals in the treatment of CSA as outlined in the treatment guidelines developed by Ford and Cloitre (2009).

In contrast to many treatment models for sexual abuse, which involve re-telling the story, normalising the emotions, decreasing avoidance, and facilitating integration of the self (Radford et al. 2014), the group intervention did not focus on re-experiencing the trauma event. The intervention rather focused on facilitating self-awareness and development of selfesteem and interpersonal relationships. In the group context their emotions were normalised by the awareness that others have similar emotional experiences. They learned coping skills by observing how other participants cope with their emotions. The art activities encouraged exploration and indirect expression of emotions and the reflective discussions contributed to the reconstruction of their lives and developing a sense of mastery. The group intervention thus used indirect ways to achieve similar results as individual trauma counselling (Cook et al. 2005, Ford and Cloitre 2009, Radford et al. 2014), without the risk of re-traumatising the 
participants. Participants in this research found value in not being required to talk about the sexual abuse, as some expressed distress at having to relive or talk about the trauma.

The advantage of using an expressive art group intervention in low resource areas is that more victims of sexual abuse can have access to treatment at a given time than individual counselling allows. While individual counselling has to be conducted by trained professionals, the group intervention can be implemented by non-professionals under supervision of a professional, as was done in this research. The possibility that counsellors and trained community workers can implement such group interventions need to be investigated. This can relieve the burden on the few trained therapists working in the field and can decrease the cost of treatment.

Group interventions can be seen as resource-effective treatment programmes (Petersen et al. 2005) when compared to one-on-one trauma debriefing that should only be performed by trained professionals. This intervention could potentially be regarded as a cost-effective intervention. The material used was low-cost materials such as paper, coloured crayons and glue. It was implemented by students-in-training with supervision of a professional. Having four group facilitators contributed to the initiative taken by the facilitators, but is not necessary in the implementation process. It is preferred that one facilitator and one cofacilitator implement such an intervention. It is not necessary to have only female facilitators. Male facilitators could assist the girls to develop new perspectives of men and to re-gain trust. To ensure ethical conduct a professional supervisor is necessary if non-professionals implement such an intervention. The supervisor should meet facilitators after each session to help facilitators to understand the group process, individual reactions and the expression of trauma symptoms to be able to plan their activities accordingly. In a task sharing version of this intervention (Rispel et al. 2010, World Health Organization, 2007) the selection of 
emotionally sensitive facilitators, skills training and continuous supervision and support of facilitators are important requirements for effective implementation.

\section{Strengths and limitations of the research}

The researcher used multiple forms of data collection such as group process notes, interviews and quantitative surveys to gain access to the participants' experiences of the intervention. The data from various sources was integrated to increase the trustworthiness of the data and the transferability of the results, as it produced a rich description of the participant's experience of the intervention (Morse et al. 2002). The researcher purports that similar groups in similar contexts would likely experience similar benefits to the ones described by the group members.

The researcher had a double role as co-facilitator of the group and interviewer which could have influenced the researcher's perspective and analysis of the data. This serves as both a strength and limitation to this study. The researcher developed trusting relationships with the participants. These relationships could have had an effect on the research process as the participants were comfortable to share personal information with the researcher which led to richer data. It could also be considered a limitation as it is possible that participants may have censored their responses or elaborated on information during the post-intervention interview to be conducive to their perception of the researcher's perspectives. They may have presented themselves favourably to gain approval of the researcher. If a researcher not known to the participants have conducted the post-intervention interviews, this limitation would have been addressed. The researcher's involvement in the intervention could also have influenced her interpretation of the results. To add to the trustworthiness of the interpretation, a coresearcher also interpreted the data independently and compared the analysis with that of the researcher. 
The group intervention and interviews were conducted in English, because all participants were semi-fluent in English. An interpreter was available that could translate words into Sepedi where needed. The language used in the research could have influenced the girls' understanding and ability to express their emotions. Although the interpersonal closeness scale assesses general interpersonal characteristics which could be universal, there is no evidence that the scale was used and is valid in the South African context.

This research was conducted with a small sample of six participants. The small sample allowed for an effective intervention, but reduces the transferability of the findings (Morse et al. 2009).

\section{Conclusion}

The participants reported that the expressive art group intervention was an enriching experience that improved their self-esteem, their relationships, and their ability to cope with negative emotions. The promising results of this study that explored the feasibility of the intervention, can be used to motivate for a more extensive evaluation of its effectiveness through an experimental design. This can contribute to appropriate and cost-effective interventions for large numbers of victims of abuse. Radford et al. (2014) highlighted the lack of empirically supported treatments available for CSA. They also commented on the methodological limitations in research on treatment of sexual abuse, including the use of small sample sizes and lack of experimental designs and comparison conditions (Radford et al. 2014). An extended study to test effectiveness of this group intervention compared to a control group or other interventions can contribute to the gap in intervention research and add to evidence-based interventions for CSA in the South African context. 


\section{$\underline{\text { References }}$}

Backos A, Pagon B. 2011. Finding a voice: art therapy with female adolescent sexual abuse survivors. Journal of the American Art Therapy Association 16(3): 126-132.

Becker L, Duncan M. 2010. Thinking about groups. In L Becker (Ed.), Working with groups (pp. 31-51). South Africa, Cape Town: Oxford University Press Southern Africa (Pty) Ltd.

Bowers C. 2011. 48 self-esteem activities for women: powerful exercises for overcoming low self-esteem plus 50 positive affirmations on how to love yourself. USA: CreateSpace Independent publishing platform.

Braun V, Clark V. 2006. Using thematic analysis in psychology. Qualitative Research in Psychology, 3(2), 77-101.

Carey PD, Walker JL, Rossouw W, Seedat S, Stein DJ. 2008. Risk indicators and psychopathology in traumatised children and adolescents with a history of sexual abuse. European Child and Adolescent Psychiatry 17: 93-98.

Children's Act. 2005. No. 38 of 2005. Government Gazette, 28944, 610. Available at www.saflii.org/za/legis/consol_act/ca2005104.pdf

Choi KW, Sikkema KJ, Velloza J, Marais A, Jose C, Stein D, Watt MH, Joska JA. 2015. Maladaptive coping mediates the influence of childhood trauma on depression and PTSD among pregnant women in South Africa. Archives of women's mental health. Archives of women's mental health 01/2015; DOI: 10.1007/s00737-015-0501-8.

Coholic D. 2010. Art activities for children and young people in need: helping children to develop mindfulness, spiritual awareness and self-esteem. United Kingdom: Jessica Kingsley. 
Collie K, Backos A, Malchiodi C, Spiegal D. 2006. Art therapy for combat-related PTSD: recommendations for research and practice. Journal of the American Art Therapy Association 23(4):157-164.

Cook A, Spinazzola J, Ford J, Lanktree C, Blaustein M, Cloitre M, van der Kolk B. 2005. Complex trauma in children and adolescents. Psychiatric Annals 35: 390.

Creswell JW. 2003. Research design, qualitative, quantitative and mixed methods approaches, second edition. Sage: Thousand Oaks.

Edwards DJA. 2009. Treating post-traumatic stress disorder in South Africa: An integrative model grounded in case-based research. Journal of Psychology in Africa 19(2):189198.

Farham B, Mabasa N, Lee N, Seggie J, Riet H. 2013. Best of 2012: Trauma and PTSD. The SA Journal of CPD CME 31(2): 49-52.

Ford JD, Cloitre M. 2009. Best practices in psychotherapy for children and adolescents. In: Courtois CA, Ford JD (ed.). Treating complex stress disorders: An evidence based guide. New York: Guilford Press. pp 59-81.

Garthoeffner JL, Henry CS, Robinson LC. 1993. The modified Interpersonal Relationship Scale: Reliability and validity. Psychological Reports 73: 995- 1004. http://dx.doi.org/10.2466/pr0.1993.73.3.995

Gravetter FJ, Forzano LAB. 2009. Research methods for the behavioral sciences (3rd edition). Belmont: Wadsworth.

Gregorowksi C, Seedat S. 2013. Addressing childhood trauma in a developmental context. Journal of Child and Adolescent mental health 25(2): 105-118. 
Hajiyiannis H, Robertson R. 1999. Counsellors' appraisals of the wits trauma counselling model: Strengths and limitations. Paper presented at the traumatic stress in South Africa - working towards solutions conference, Johannesburg, South Africa.

Hirschowitz R, Worku S, Orkin M. 2000. Quantitative research findings on rape in South Africa. Statistics South Africa report.

Jewkes R, Penn-Kekana L, Rose-Junius H. 2005. "If they rape me, I can’t blame them”: Reflections on gender in the social context of child rape in South Africa and Namibia. Social Science \& Medicine 61(8): 1809-1820.

Kaminer D. 2006. Healing processes in trauma narratives: A review. South African Journal of Psychology 36(3), 481-466.

Lilienfeld S, Lynn SJ, Lohr JM. 2003. Science and pseudoscience in clinical psychology. New York, USA: The Guilford Press.

Makin JD, Forsyth BWC, Visser MJ, Sikkema KJ, Neufeld S, Jeffery B. 2008. Factors affecting disclosure in South African HIV positive pregnant women. AIDS Patient Care and STDs 22(11): 907-916.

Malchiodi CA. 2005. Expressive therapies: History, theory and practice. New York: Guilford Press.

Mash E, Wolfe DA. 2012. Abnormal Child Psychology (5th edition). Belmont, USA: Wadsworth Publishing.

Meel BL. 2008. Trends of rape in the Mthatha area, Eastern Cape, South Africa. South African Family Practice 50(1): 69-69. doi: 10.1080/20786204.2008.10873675 
Moffett H. 2006. 'These women, they force us to rape them': Rape as Narrative of Social Control in Post-Apartheid South Africa. Journal of Southern African Studies 32(1): $129-144$.

Morse JM, Barrett M, Mayan M, Olson K, Spiers J. 2002. Verification strategies for establishing reliability and validity in qualitative research. International Journal of Qualitative Methods 2(1): 13-22.

Murphy J. 2001. Art Therapy with Young Survivors of Sexual Abuse. USA: Taylor \& Francis.

Olafson E. 2014. Child sexual abuse: Demography, impact, and interventions. Journal of Child \& Adolescent Trauma 4(1): 8-21. doi:10.1080/19361521.2011.545811

Oz S. 2010. Treatment of individuals and families affected by child sexual abuse: Defining professional expertise. Journal of Child Sexual Abuse 19(1):1-19.

Penning SL, Collings SJ. 2014. Perpetration, revictimization, and self-injury: Traumatic reenactments of child sexual abuse in a nonclinical sample of South African adolescents. Journal of Child Sexual Abuse 23(6): 708-726.

Petersen I, Bhana A, McKay M. 2005. Sexual violence and youth in South Africa: The need for community-based prevention interventions. Child Abuse \& Neglect 29:1233-1248. doi: 10.1016/j.chiabu.2005.02.012

Pifalo T. 2011. Pulling out the thorns: Art therapy with sexually abused children and adolescents. Journal of the American Art Therapy Association 19(1): 12-22.

Radford L, Allnock D, Hynes P. 2014. Presenting and responding to child sexual abuse and exploitation: Evidence review summary. Paper presented at the $6^{\text {th }}$ annual sexual offences INDABA, Johannesburg, South Africa.

Rape Crisis. 2012. Supporting recovery. Seeking justice. Making changes. Retrieved from http://rapecrisis.org.za/ 
Rispel L, Moorman J, Chersich M, Goudge J, Nxumalo N, Ndou T. 2010. Revitalising primary health care in South Africa: review of primary health care package, norms and standards. Johannesburg: Centre for Health Policy, University of the Witwatersrand.

Robertson M. 2011. An overview of rape in South Africa. Center for the Study of Violence and Reconciliation. http://www.csvr.org.za/articles/artrapem.htm (accessed 11 January 2015).

Rodriguez-srednicki O. 2002. Childhood sexual abuse, dissociation, and adult self-destructive behavior. Journal of Child Sexual Abuse 10(3): 75-89. doi: 10.1300/J070v10n03_05

Rosenberg M. 1965. Society and the adolescent self-image. Princeton, NJ: Princeton University Press.

Sadock BJ, Sadock VA. 2007. Synopsis of psychiatry (Tenth edition). New York: Lippincott Williams \& Wilkins.

Saiger GM, Rubenfeld S, Dluhy MD. 2008. Windows into today's group therapy. USA: Taylor \& Francis Group.

Smith JA. 2004. Reflecting on the development of interpretive phenomenological analysis and its contribution to qualitative to qualitative research in psychology. Qualitative research in psychology 1: 39-54.

Smith K, Bryant-Davis T, Tillman S, Marks, A. 2010. Stifled voices: barriers to help-seeking behavior for South African childhood Sexual Assault Survivors. Journal of Child Sexual Abuse 19(3): 255-274. doi: 10.1080/10538711003781269.

Snyder CR, Lopez JL, Pedrotti JT. 2011. Positive psychology: the scientific and practical explorations of human strengths (2nd edition). USA: Sage publications, Inc. 
South African Police Service (SAPS). 2014. Crime statistics: April 2013 - March 2014. Available at http://www.saps.gov.za/resource_centre/publications/statistics/crimestats /2014/crime_stats.php

Spies GM 2006. The effect of sexual abuse on a child. In GM Spies (Ed.). Sexual abuse: dynamics, assessment \& healing. Pretoria: Van Schaik.

Sturgeon S, Keet N. 2010. Groupwork and mental health. In L Becker (Ed.). Working with groups (pp. 153-165). South Africa, Cape Town: Oxford University Press Southern Africa (Pty) Ltd.

Suliman S, Mkabile, SG, Fincham, DS, Ahmed, R, Stein DJ, Seedat S. 2009. Cumulative effect of multiple trauma on symptoms of posttraumatic stress disorder, anxiety, and depression in adolescents. Comprehensive Psychiatry 50: 212-127.

Tierney DW, McCabe M. 2002. Motivation for behavior change among sex offenders: a review of the literature. Clinical psychology review 22(1): 113-129. doi: 10.1016/S0272-7358(01)00084-8

Wassenaar K. 2006. Ethical issues in social research. In Terre Blanche M, Durrheim K, Painter D (eds.), Research in practice: applied methods for the social sciences (2nd edition). South Africa, Cape Town: University of Cape Town Press. pp 84-98.

Wilkinson K. 2014. Is a child raped every three minutes in South Africa? The data is flawed, African Check https://africacheck.org/reports/is-a-child-raped-every-three-minutes-insouth-africa-the-statistic-is-flawed/

World Health Organisation (WHO) 2007. Treat Train and Retrain. Task shifting: global recommendations and guidelines. Geneva: WHO.

Yalom ID 1985. The theory and practice of group psychotherapy. USA: Basic Books Inc. 